\title{
DESIGNING ALGORITHMS FOR SOLVING PHYSICS PROBLEMS ON THE BASIS OF MIVAR APPROACH
}

\section{Chuvikov D.A., Nazarov K.V.}

The paper considers the process of designing algorithms for solving physics problems on the basis of mivar approach. The work also describes general principles of mivar theory. The concepts of parameter, relation and class in mivar space are considered. There are descriptions of properties which every object in Wi!Mi model should have. An experiment in testing capabilities of the Wi!Mi software has been carried out, thus the model has been designed which solves physics problems from year 8 school course in Russia. To conduct the experiment a new version of Wi!Mi 2.1 software has been used. The physics model deals with the following areas: thermal phenomena, electric and electromagnetic phenomena, optical phenomena.

Keywords: algorithm calculation; mivar; Wi!Mi 2.1; "physics» subject domain; expert system; mivar networks; mivar-based approach.

\section{Introduction}

The developing information systems and technologies require new automated and intellectual software systems such as ACS (Automated Control System), ADPS (Automated Data Processing System), APCS (Automated Process Control Systems) and DSS (Decision Support Systems) [1]. Currently, there are many approaches to data processing and data representation. It should be noted that mivar-based approach becomes increasingly popular. This approach processes large volumes of data in real time, which allows us to describe various subject domains 
the most comprehensively. Each solution is unique for each specific situation and built automatically without the need of expert involvement.

\section{Description of mivar theory}

Mivar theory is rather wide and due to its universality covers many objects of everyday life [2]. For example, it covers the field of ADPCS (Automated Data Processing and Control Systems) and its modelling.

One of the main features of mivar theory is data representation in the form of semantic graph "Object-Property-Relation" (VSO) [2-15].

Mivar space represents a set of axes, a set of axes elements, a set of points of space and a set of values of points [9]. Let us introduce $A=\left\{a_{n}\right\}, n=1 . . N$, where $A$ is a set of mivar space axis names and $N$ is a number of mivar space axes. Then

$$
\forall a_{n} \exists F_{n}=\left\{f_{n_{i}}\right\}, n=1 . . N, i_{n}=1 . . I_{n}
$$

where $F_{n}$ is a set of axis $a_{n}$ elements, $i_{n}$ is set $F_{n}$ element identifier, $I_{n}=\left|F_{n}\right| . F_{n}$ sets form multidimensional space: $M=F_{1} \times F_{2} \times \ldots \times F_{n}$. $\mathrm{m}=\left(\mathrm{i}_{1}, \mathrm{i}_{2}, . ., \mathrm{i}_{\mathrm{N}}\right), \mathrm{m} \in \mathrm{M}$, where $\mathrm{m}$ is a point of multidimensional space, $\left(i_{1}, i_{2}, . ., i_{N}\right)$ are coordinates of point $m[6]$.

There is a set of values of multidimensional space points of $\mathrm{M}$ :

$\mathrm{C}_{\mathrm{M}}=\left\{\mathrm{c}_{\mathrm{i} 1}, \mathrm{i}_{2}, . ., \mathrm{i}_{\mathrm{N}} \mid \mathrm{i}_{1}=1 . . \mathrm{I}_{1}, \mathrm{i}_{2}=1 . . \mathrm{I}_{2}, . . \mathrm{i}_{\mathrm{n}}=1 . . \mathrm{I}_{\mathrm{N}}\right\}$, where $\mathrm{c}_{\mathrm{i} 1}, \mathrm{i}_{2}, . ., \mathrm{i}_{\mathrm{N}}$ is a value of the point of multidimensional space $\mathrm{M}$ with coordinates $\left(i_{1}, i_{2}, \ldots, i_{N}\right)$. For every point of space $M$ there is a single value from $\mathrm{C}_{\mathrm{M}}$ set or there is no such value. Thus, $\mathrm{C}_{\mathrm{M}}$ is a set of data model state changes represented in multidimensional space. To implement a transition between multidimensional space and set of points values the relation has been introduced: $C_{x}=\mu\left(M_{x}\right)$, where $M_{x} \subset M, M_{x}=$ $\mathrm{F}_{1 \mathrm{x}} \times \mathrm{F}_{2 \mathrm{x}} \times \ldots \times \mathrm{F}_{\mathrm{Nx}}$.

To describe a data model in mivar information space it is necessary to identify three axes:

- The axis of relations $« \mathrm{O} »$;

- The axis of attributes (properties) « $\mathrm{S} »$;

- The axis of elements (objects) of subject domain «V». 
The axes «V», «S», «O» are presented in Fig. 1 [6]. These sets are independent. The mivar space can be represented by the following tuple:

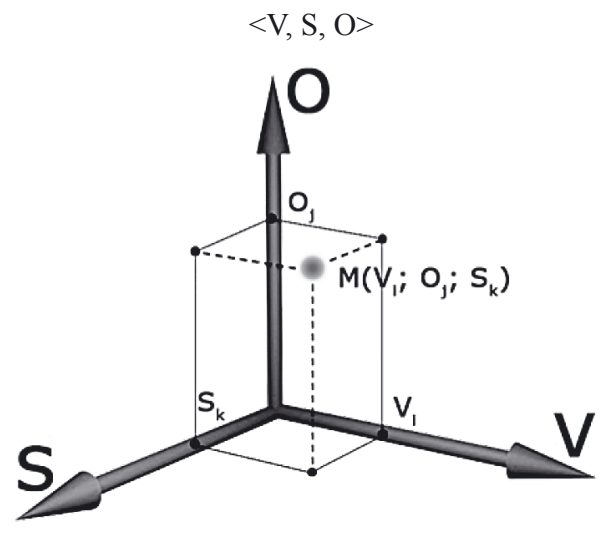

Fig. 1. Mivar information space

The point with certain coordinates corresponds to each relation attribute value in multidimensional space. Relations connect elements of the space. The set of all multidimensional space points corresponds to the data model. The structure of the model in mivar approach is defined by space points that store corresponding relation attribute values. Mivar network can be represented in the form of a bipartite graph [5-6].

One of basic concepts of the proposed mivar-based approach is the concept of mivar network [6]. Generally, mivar network provides formalization and representation of human knowledge in the form of connected multidimensional space. That is, mivar network is a method of representing a piece of mivar space information in the form of a bipartite directed graph. The mivar space information is formed by objects and connections between them, which in total represent the data model of the subject domain, moreover, connections include rules for objects processing. Thus, mivar network of subject domain is a part of mivar space knowledge in this domain. 
Mivar networks can be represented in the form of a bipartite graph consisting of objects-variables and rules-procedures. First, two lists are made which form two nonintersecting partitions of the graph: the list of objects and the list of rules. Objects are denoted by circles. Each rule in mivar network is extension of productions, hyper rules with multi-activators. It is proved that from the perspective of their further processing, all these formalisms are identical and in fact they are nodes of the bipartite graph which are denoted by rectangles [12].

\subsection{Parameters and classes in mivar space}

Parameter is a single terminal object that has meaning on this abstraction level. The length of the side $\mathrm{AB}$ of the triangle $\mathrm{ABC}$ can be used as an example. Parameter is a leaf in the element hierarchy tree in the model. Parameter can be connected with only one internal node (class) [1].

Class is an internal node of the hierarchy tree. Class has no meaning and can contain other internal nodes (other classes) or/and leaves (parameters). For example, class can be a "triangle" that stores parameters of the sides and angles. Class can be a "division", which can contain not only its parameters (name, list number, location, etc.), as well as other classes, for example, rotas. The introduction of classes allows us to simplify description of the model containing several objects of the same type. The user does not have to enter all the information again and search for parameters in the whole model. It is sufficient to copy and enter a new instance. One more difference between class and parameter is that class can contain the list of internal rules of the class.

Internal rule of the class is a rule enabling only parameters that are descendants for a particular class. For example, internal rule for a triangle will be "angle C $=180$ - angle B" since all these angles are descendant parameters of the class "triangle". Introduction of internal class rules allows us to simplify development of similar objects according to the pattern, as internal rules will be automatically generated 
for a new class instance. Except for this, they do not differ from simple rules.

\subsection{Relations in mivar space}

Relations are a renewed element of mivar space. Relation describes interconnection between abstract variables. For example, " $\mathrm{a}=\mathrm{b}-\mathrm{c}$ " is an abstract subtraction formula. Relation stores its type, the list of input variables and the list of output variables, types of used variables and description.

Relations can be as follows:

1. Mathematical. A simple formula " $\mathrm{a}=\mathrm{b}-\mathrm{c}$ " can be an example;

2. Conditional. For example, "if $\mathrm{y}$ is 10 , then $\mathrm{x}$ is 14 , else $\mathrm{x}$ is 7 ";

3. Programmable. Software code with its inputs and outputs can be used as an example.

4. String. For example, "loves", "connected".

5. System. "The part-the whole".

6. Location. For example, "over", "right", etc.

The rule contains the link to the relation and connects particular objects from the model. It is designed to simplify description of subject domains and repeated use of the same even complex programmable properties. For example, we have a mathematical relation with the formula " $a=b-c$ ". It can denote account balance after paying something, as well as the number of apples, if we had 10 apples and gave one to somebody.

Rules contain at least:

1. The list of input variables;

2. The list of output variables;

3. Relation identifier.

It should be noted that the mivar constraints mechanism has been proposed, which allows us to transmit information about the real world more accurately and track its change. Due to constraints it is possible to signal any emergency in Automated Process Control Systems or indicate wrong input data [1]. 


\section{Description of model design in the system Wi!Mi}

There is special Wi!Mi software, which allows us to represent all the data in the form of the mivar semantic graph VSO [2-14]. Using the Wi!Mi software, the user can design a model of his subject domain, which will be a logical kernel for a particular modelling task.

When designing a model in the Wi!Mi system, each object should have the following properties:

- It should have the unique identifier (UID);

- It should have a name;

- It can have a description;

- It should have a type (number, text, flag, etc.);

- It can have value;

- It should have constraints for values;

- It should have one or several characteristics that either belong to the object or they are inherited through connection (using object-oriented approach). It is also necessary to designate the object from which inheritance is implemented.

- It can be located on a certain level in the hierarchy (using object-oriented approach)

- It can have any number of connections with other objects of the model.

Thus, the following conclusion can be drawn: Wi!Mi platform is a convenient designer for describing logical rules of any subject domains. The user is only required to set parameters for a particular subject domain.

\section{Designing algorithms for solving physics problems.}

As an experiment in testing capabilities of Wi!Mi software, the model has been designed, which allows us to solve physics problems from the year 8 school course. To carry out the experiment a new version of software product Wi!Mi 2.1 was used. Structurally the model consists of three subclasses corresponding to the subject matter of the problems being solved: 
- Thermal phenomena;

- Electrical and electromagnetic phenomena;

- Optical phenomena.

\subsection{The subclass "Thermal phenomena"}

The subclass "Thermal phenomena" is used to solve problems related to change in body temperature and interrelated processes. This subclass in described in the Table 1.

Table 1.

The description of the subclass "Thermal phenomena"

\begin{tabular}{|c|c|c|l|}
\hline № & Symbol & Type & \multicolumn{1}{|c|}{ Description } \\
\hline & $\mathrm{Q}$ & number & The quantity of heat $[\mathrm{J}]$ \\
\hline & $\mathrm{m}$ & number & mass $[\mathrm{kg}]$ \\
\hline & $\Delta \mathrm{t}$ & number & $\left(\mathrm{t}_{2}-\mathrm{t}_{1}\right)-$ difference of temperature $\left[{ }^{\circ} \mathrm{C}\right]$ \\
\hline & $\mathrm{t} 1$ & number & Initial temperature $\left[{ }^{\circ} \mathrm{C}\right]$ \\
\hline & $\mathrm{t} 2$ & number & Final temperature $\left[{ }^{\circ} \mathrm{C}\right]$ \\
\hline & $\mathrm{c}$ & number & Specific heat capacity $[\mathrm{J} / \mathrm{kg} \cdot \mathrm{C}]$ \\
\hline & $\mathrm{q}$ & number & Specific heat of fuel combustion $[\mathrm{J} / \mathrm{kg}]$ \\
\hline & $\lambda$ & number & $($ ) specific heat of fusion $[\mathrm{J} / \mathrm{kg}]$ \\
\hline & $\mathrm{L}$ & number & Specific heat of vaporization $[\mathrm{L} / \mathrm{kg}]$ \\
\hline & Q fusion & number & The quantity of heat during fusion $[\mathrm{J}]$ \\
\hline & Q combustion & number & The quantity of heat during heating $[\mathrm{J}]$ \\
\hline & Q vaporization & number & The quantity of heat during combustion $[\mathrm{J}]$ \\
\hline & $\mathrm{V}$ & number & Volume of body $/$ liquid $/ \mathrm{gas}\left[\mathrm{m}^{3}\right]$ \\
\hline & $\rho$ & number & Density of body $/$ liquid $/$ gas $\left[\mathrm{kg} / \mathrm{m}^{3}\right]$ \\
\hline & COP & number & The coefficient of performance $[\%]$ \\
\hline & A useful & number & Useful work $[\mathrm{J}]$ \\
\hline & A done & number & Work done $[\mathrm{J}]$ \\
\hline
\end{tabular}

Let us solve the following problem:

Determine the COP of tractor engine that required $1,5 \mathrm{~kg}$ of fuel with specific heat of combustion 4,2 107 to perform work of $1,89 \cdot 107 \mathrm{~J}$.

Enter the corresponding numbers into the fields "Values" (Fig. 2). 


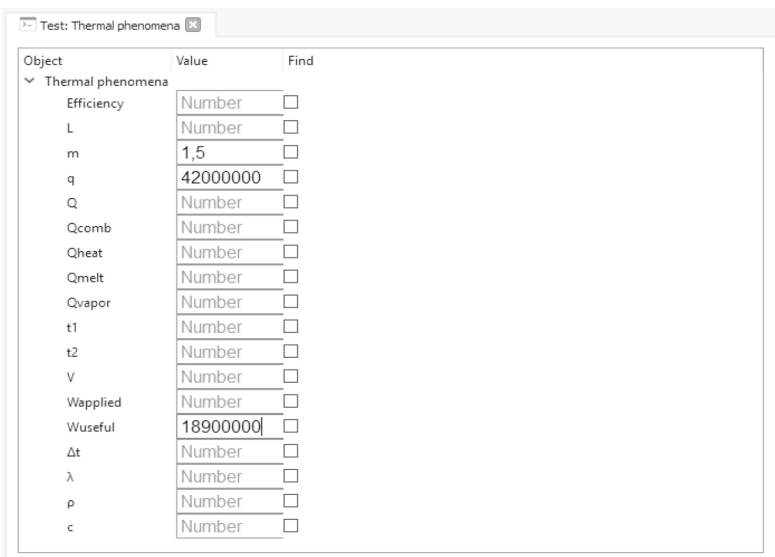

Fig. 2. Fields with corresponding numbers in the subclass "Thermal phenomena"

Next, click on the checkbox "Find" in the row with the required parameter. In this case this parameters is "COP" as it is required to find this parameters according to the problem statement.

After clicking on the "Run" button, the Wi!Mi 2.1 software will implement the calculation. The corresponding parameters will acquire given values (they will be highlighted in red) (Fig. 3):

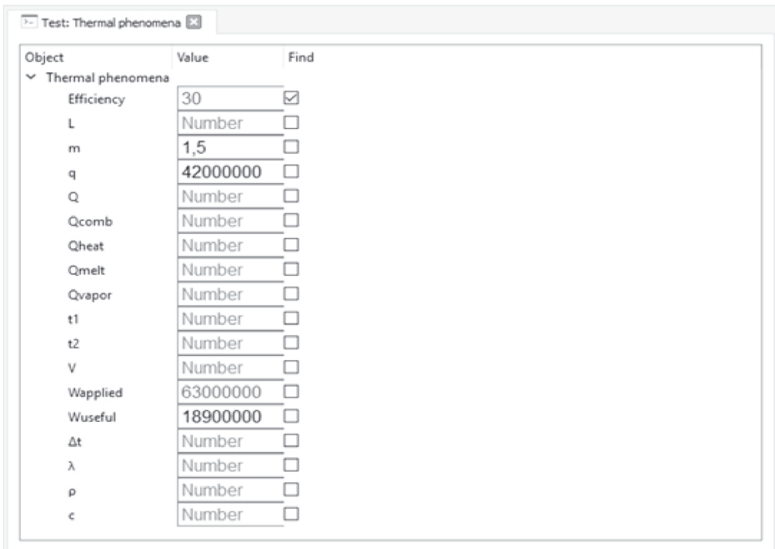

Fig. 3. The result of the calculation in the subclass "Thermal phenomena" 


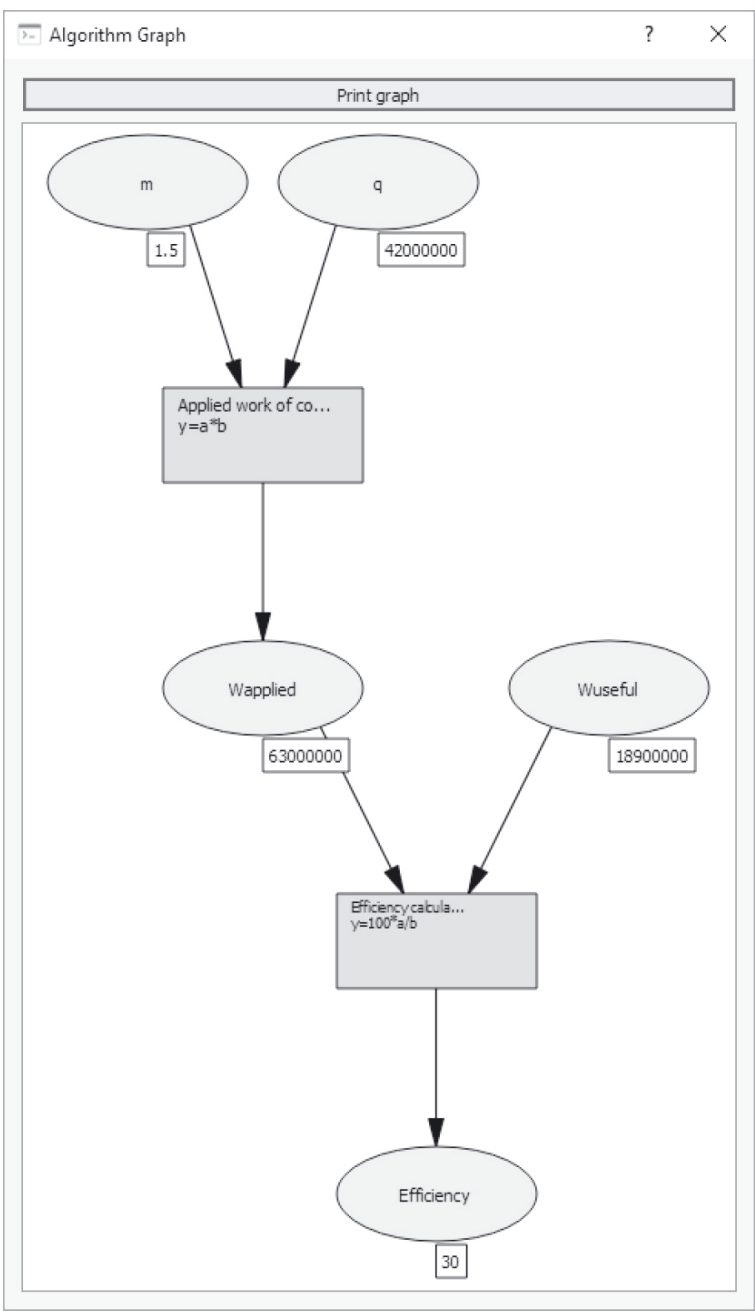

Fig. 4. Algorithm for finding COP parameter in the form of the graph

The corresponding output will appear in the tab "Console":

Step № 0

Rule description: The calculation of the work done during combustion $($ A done $=\mathrm{mq})$ 
Input parameters:

$\mathrm{m}=1.5$;

$\mathrm{q}=42000000$;

Formula:

$\mathrm{y}=\mathrm{a} * \mathrm{~b}$

Result: A done $=63000000$;

Step № 1

Rule description: The calculation of COP using the known work ( $\mathrm{n}=\mathrm{A}$ useful/A done*100)

Input parameters:

A useful $=18900000$;

A done $=63000000$;

Formula:

$y=100 * a / b$

Result: $\mathrm{COP}=30$;

Fig. 4 represents the result of the calcultion in the form of a graph. The obtained result corresponds to analytical solution:

$$
\begin{aligned}
& C O P=\frac{A_{\text {useful }}}{A_{\text {done }}} \cdot 100 \%=\frac{A_{\text {useful }}}{q m} \cdot 100 \%= \\
& =\frac{1,89 \cdot 10^{7} \cdot \mathrm{J}}{4,2 \cdot 10^{7} \frac{\mathrm{J}}{\mathrm{kg}} \cdot 1,5 \mathrm{~kg}} \cdot 100 \%=0,3 \cdot 100 \%= \\
& =30 \%
\end{aligned}
$$

\subsection{The subclass}

"Electrical and electromagnetic phenomena"

The subclass "Electrical and electromagnetic phenomena" is used to solve problems associated with concepts of current intensity, voltage, resistance. This subclass is described in the Table 2. 
Table 2.

Description of the subclass "Electrical and electromagnetic phenomena"

\begin{tabular}{|c|c|c|l|}
\hline № & Symbol & Type & \multicolumn{1}{c|}{ Description } \\
\hline & $\mathrm{I}$ & number & Current intensity $[\mathrm{A}]$ \\
\hline & $\mathrm{q}$ & number & Electric charge $[\mathrm{Kd}]$ \\
\hline & $\mathrm{t}$ & number & time $[\mathrm{s}]$ \\
\hline & $\mathrm{U}$ & number & voltage $[\mathrm{V}]$ \\
\hline & $\mathrm{A}$ & number & work $[\mathrm{J}]$ \\
\hline & $\mathrm{R}$ & number & resistance $[\mathrm{Ohm}]$ \\
\hline & $\rho$ & number & Specific resistance $\left[\mathrm{Ohm} \cdot \mathrm{mm}^{2} / \mathrm{m}\right]$ \\
\hline & $\mathrm{dl}$ & number & length $[\mathrm{m}]$ \\
\hline & $\mathrm{s}$ & number & cross-sectional area $\left[\mathrm{mm}^{2}\right]$ \\
\hline & $\mathrm{Ai}$ & number & Work of current $[\mathrm{J}]$ \\
\hline & $\mathrm{P}$ & number & Power $[\mathrm{W}]$ \\
\hline & $\mathrm{Q} i$ & number & The quantity of heat generated by the conductor $[\mathrm{J}]$ \\
\hline
\end{tabular}

Let us solve the following problem:

The current intensity in the iron conductor with the length of 150 $\mathrm{mm}$ and cross-sectional area of $0,02 \mathrm{~mm} 2$ is $250 \mathrm{~mA}$. What is the voltage at the ends of the conductor, if specific resistance of iron is $0,098 \mathrm{ohm} \cdot \mathrm{mm} 2 / \mathrm{m}$. Enter the corresponding numbers into the fields "Values" (Fig. 5).

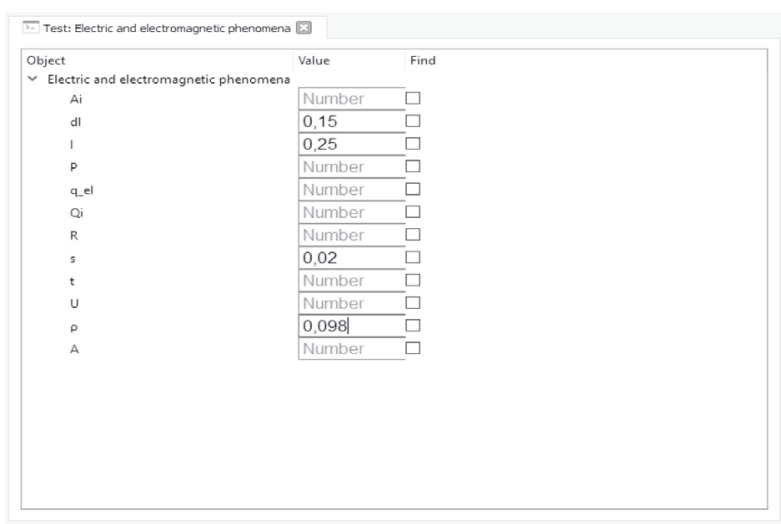

Fig. 5. Fields with corresponding numbers in the subclass "Electrical and electromagnetic phenomena" 
Next, click on the checkbox "Find" in the row with the required parameter. In this case this parameters is "U"(voltage) as it is required to find this parameters according to the problem statement.

After clicking on the "Run" button, Wi!Mi 2.1 software will implement the calculation. The corresponding parameters will acquire given values (they will be highlighted in red) (Fig. 6):

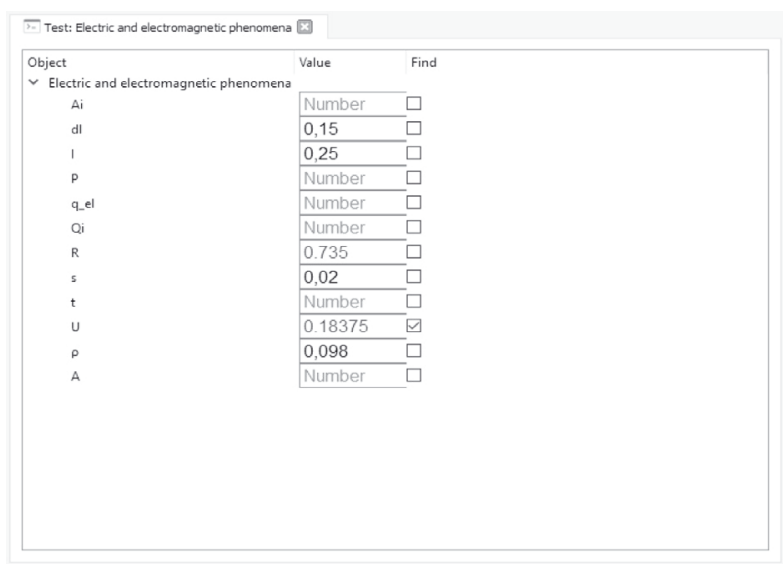

Fig. 6. The result of the calculation in the subclass

"Electrical and electromagnetic phenomena"

The corresponding output will appear in the tab "Console":

Step \# 0

Rule description: The calculation of resistance using the known parameters of the conductor $(\mathrm{R}=\mathrm{ro} * \mathrm{dl} / \mathrm{s})$

Input parameters:

$\rho=0.098$;

$\mathrm{dl}=0.15$;

$\mathrm{s}=0.02$;

Formula:

$\mathrm{y}=\mathrm{a} * \mathrm{~b} / \mathrm{c}$

Result: $\mathrm{R}=0.735$; 
Step \# 1

Rule description: The calculation of voltage using Ohm's law (U=IR) Input parameters:

$\mathrm{I}=0.25$;

$\mathrm{R}=0.735$;

Formula:

$\mathrm{y}=\mathrm{a} * \mathrm{~b}$

Result: $\mathrm{U}=0.18375$;

Fig. 7 represents the result of the calculation in the form of a graph.

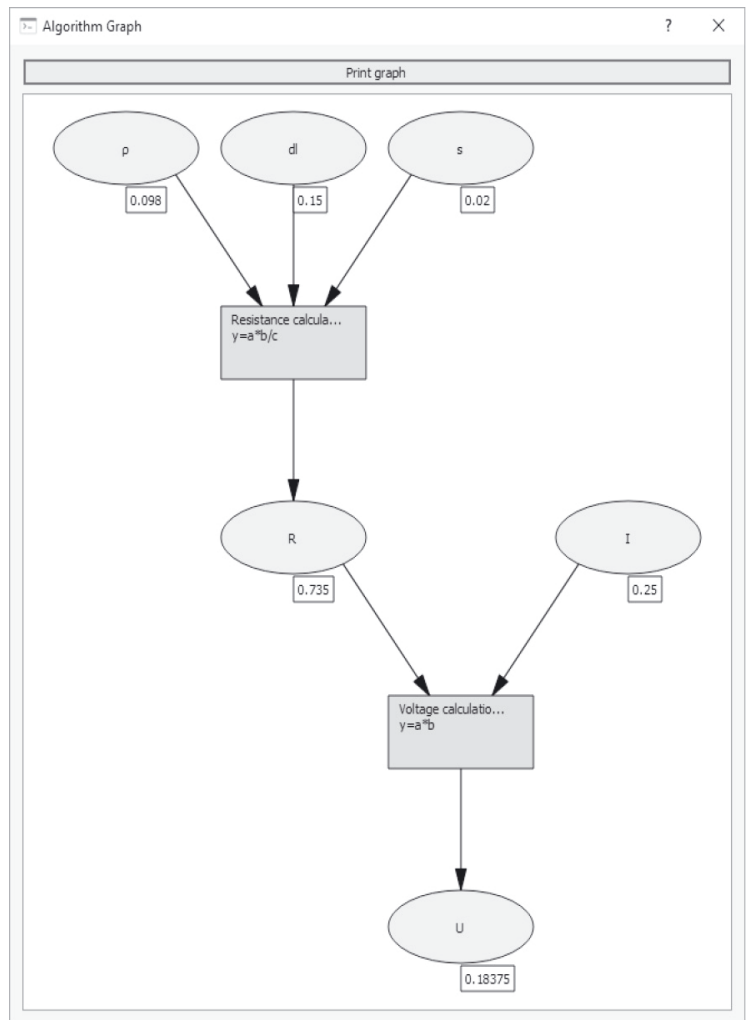

Fig. 7. Algorithm for finding U parameter (voltage) in the form of a graph 
The obtained result corresponds to analytical solution:

$$
\begin{aligned}
& U=I R=I \frac{\rho \cdot \Delta l}{S}= \\
& =250 \cdot 10^{-3} \mathrm{~A} \cdot \frac{0,098 \frac{\mathrm{Ohm} \cdot \mathrm{mm}^{2}}{\mathrm{~m}} \cdot 150 \cdot 10^{-3} \mathrm{~m}}{0,02 \mathrm{~mm}^{2}}= \\
& =0,18375 \mathrm{~V}
\end{aligned}
$$

\subsection{The subclass "Optical phenomena"}

The subclass "Optical phenomena" is used to solve problems related to the calculation of lens parameters. This subclass is described in the Table 3.

Table 3.

Description of the subclass "Optical phenomena"

\begin{tabular}{|c|c|c|l|}
\hline № & Symbol & Type & \multicolumn{1}{c|}{ Description } \\
\hline & $\mathrm{D}$ & number & optical power of a lens $[$ dioptre] \\
\hline & $\mathrm{F}$ & number & lens focal length [m] \\
\hline & $\mathrm{d}$ & number & the distance from the object to the lens $[\mathrm{m}]$ \\
\hline & $\mathrm{f}$ & number & the distance from the lens to the image $[\mathrm{m}]$ \\
\hline
\end{tabular}

Let us solve the following problem:

The distance from an object to the thin lens is $5 \mathrm{~m}$, the distance from the lens to the image is $20 \mathrm{~m}$. Determine the focus of the lens and its optical power.

Enter the corresponding numbers into the fields "Values" (Fig. 8).

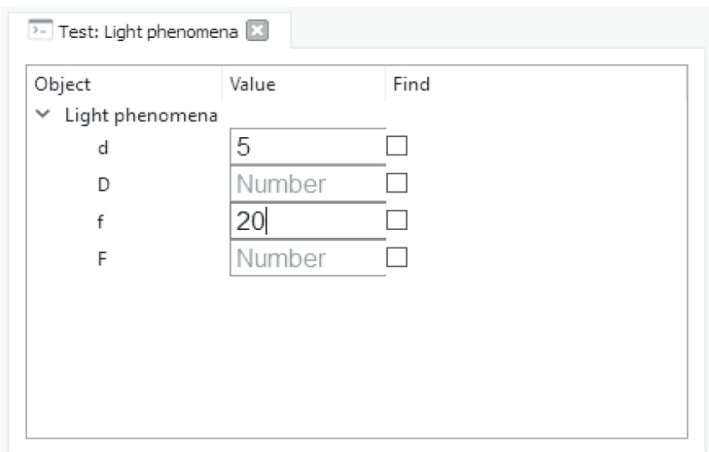

Fig. 8. Fields with corresponding numbers in the subclass "Optical phenomena" 
Next, click on the checkbox "Find" in the row with the required parameter. In this case this parameters is " $\mathrm{D}$ "(optical power) and " $F$ " (focal length) (as it is required to find this parameters according to the problem statement.

After clicking on the "Run" button, Wi!Mi 2.1 software will implement the calculation. The corresponding parameters will acquire given values (they will be highlighted in red) (Fig. 9):

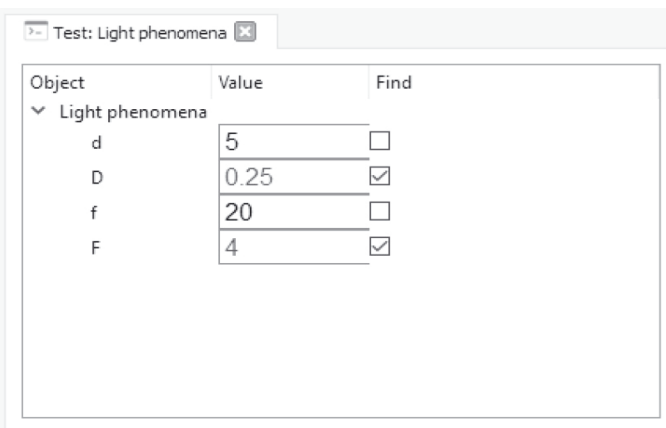

Fig. 9. The result of the calculation in the subclass "Optical phenomena"

The corresponding output will appear in the tab "Console":

Step \# 0

Rule description: The calculation of focal length using known distances to the lens $(\mathrm{F}=\mathrm{df} /(\mathrm{d}+\mathrm{f}))$

Input parameters:

$\mathrm{d}=5$;

$\mathrm{f}=20$;

Formula:

$\mathrm{y}=\mathrm{a} * \mathrm{~b} /(\mathrm{a}+\mathrm{b})$

Result: $\mathrm{F}=4$;

Step \# 1

Rule description: The calculation of optical power using the known distances to the lens $(\mathrm{D}=(\mathrm{d}+\mathrm{f}) / \mathrm{df})$ 
Input parameters:

$\mathrm{d}=5$;

$\mathrm{f}=20$;

Formula:

$\mathrm{y}=(\mathrm{a}+\mathrm{b}) / \mathrm{a} / \mathrm{b}$

Result: $\mathrm{D}=0.25$;

Fig. 10 represents the result in the form of a graph.

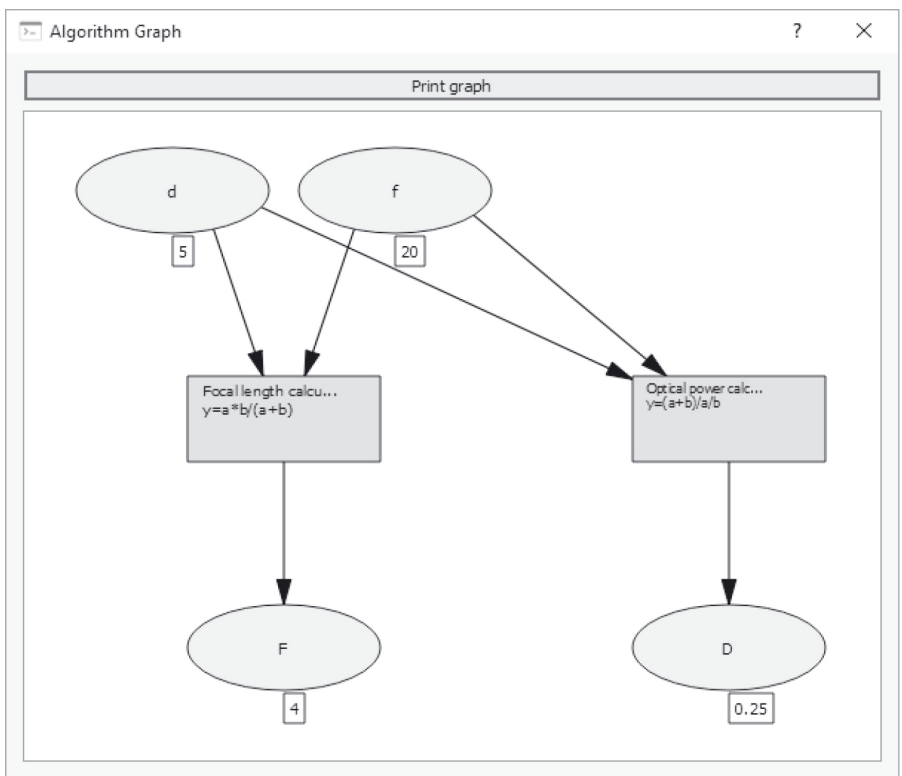

Fig. 10. Algorithm for finding parameters " $D$ " (optical power) and " $F$ " (focal length) in the form of a graph

The obtained result corresponds to analytical solution:

$$
\begin{gathered}
F=\frac{d \cdot f}{d+f}=\frac{5 m \cdot 20 m}{5 m+20 m}=4 m \\
D=\frac{1}{F}=\frac{1}{4 m}=0,25 \text { dioptre }
\end{gathered}
$$




\section{Conclusions}

Mivar-based logical inference method is universal. It can be used not only for writing simple subject domains, but also for solving complex multi-level tasks. [1]. Mivar-based approach is applied to simulation modelling. Research has been carried out, which has proved the prospect of combining mivar logical kernel and simulation modelling system [16]. Such synthesis will allow us to model behavior of objects of considered subject domain, which will allow us to test algorithms in different set conditions virtually.

The mivar theory has been considered and described in the paper. The concepts of parameters, relations and classes have been addressed. The paper also describes the process of algorithm construction for solving physics problems from the year 8 school course in Russia on the basis of software product Wi!Mi 2.1. Thus, the paper proves the value of using mivar-based method for designing expert systems.

\section{References}

1. Chibirova M.O. (2015), Mivar approach expansion: Classes and relations, Radio industry, No.3, pp. 44-54.

2. Varlamov O.O. (2005), "About the possibility of developing intelligent systems on the basis of GRID, adaptive synthesis systems Information Computational Configurations (ICC), service-oriented architectures and mivar-oriented information space" ["O vozmozhnosti sozdaniya intellektual'nyh sistem na osnove GRID, sistem adaptivnogo sinteza IVK, servisno-orientirovannoj arhitektury i mivarnogo informacionnogo prostranstva"], Proceedings of Taganrog State Radio Engineering University, No. 10, pp. 130-140.

3. Varlamov O.O. (2013), "Practical implementation of linear computational complexity of logical inference using if-then rules in mivar nets and processing of more than three million rules" ["Prakticheskaya realizaciya linejnoj vychislitel'noj slozhnosti logicheskogo vyvoda na pravilah "esli-to" v mivarnyh setyah i obrabotka bolee trekh mil- 
lionov pravil"], Automation and control in technical systems, No.1, pp. 60-97.

4. Varlamov O.O. (2007), "About the necessity of transition from artificial intelligence theory to development of active reflection theory" ["O neobhodimosti perekhoda ot teorii iskusstvennogo intellekta k razrabotke teorii aktivnogo otrazheniya], Proceedings of Southern Federal University, Vol. 77, No. 2, pp. 89-95.

5. Varlamov O.O. The review of twenty-five-year development of mivar approach to designing intelligent systems and artificial intelligence. Proceedings of NIIR. 2011, No. 1, pp. 34-44.

6. Varlamov O.O. The fundamentals of multi-dimensional information developing (mivar) space of data and rule representation. 2003. Information technologies, No. 5, pp. 42-47.

7. Varlamov O.O. Parallel information flow processing on the basis of virtual database flows. Proceedings of Universities. Electronics. 2003, No. 5, pp. 82-89.

8. 8. Varlamov O.O. (2002), "Development of adaptive mechanism of logical inference on evolutionary interactive network of hyper-rules with multi-activators managed by data flow" ["Razrabotka adaptivnogo mekhanizma logicheskogo vyvoda na ehvolyucionnoj interaktivnoj seti giperpravil s mul'tiaktivizatorami, upravlyaemoj potokom dannyh"], Artificial intelligence, No. 3, pp. 363-370.

9. Varlamov O.O. Logical artificial intelligence has been developed on the basis of mivar approach! MIVAR: active databases with linear logical inference $>3$ million rules $=>$ meaning understanding + singularity in virtual reality. Saarbrucken, Germany: LAP LAMBERT Academic Publishing Gmbh \& Co. KG, 2012. 700 p.

10. Varlamov O.O. Development of the method for paralleling multiple thread access to common database under conditions of prevention of mutual data corruption. Information technologies. 2003. No. 1. pp. 20-28.

11. Chuvikov D.A., Kazakova N.A., Varlamov O.O., Hadiev A.M. (2014), "Analysis of technologies of three-dimensional modelling and $3 \mathrm{~d}$ 
object development for different intelligent systems ["Analiz tekhnologij trekhmernogo modelirovaniya i sozdaniya $3 \mathrm{~d}$ ob"ektov dlya razlichnyh intellektual'nyh system"], Automation and control in technical systems, No. 2.1, pp. 84-97.

12. Varlamov O.O. (2005), "Development of intelligent systems on the basis of interaction between mivar-oriented information space and service oriented architecture" ["Sozdanie intellektual'nyh sistem na osnove vzaimodejstviya mivarnogo informacionnogo prostranstva i servisno-orientirovannoj arhitektury"], Artificial intelligence, No.3, pp. 13-17.

13. Varlamov O.O. (2007), "Development of active reflection theory as generalization of artificial intelligence theory and possibility of its implementation in mivar-oriented information space" ["Sozdanie teorii aktivnogo otrazheniya kak obobshcheniya teorii iskusstvennogo intellekta i vozmozhnost' ee realizacii v mivarnom infoprostranstve"], Artificial intelligence, No. 3, pp. 17-24.

14. Chuvikov D.A. (2015), Development of electronic learning resource (ELR) "MIVAR". "MIVAR" - logical artificial intelligence, Saarbrucken, Germany: LAP LAMBERT Academic Publishing Gmbh \& Co. $\mathrm{KG}, 2012.65 \mathrm{p}$.

15.Zhdanovich E.A., Chernychev K.A., Yufimychev K.A., Eliseev D.V., Chuvikov D.A. (2015), "Random algorithms calculation of service robot functioning based on mivar approach" ["Vychislenie proizvol'nyh algoritmov funkcionirovaniya servisnyh robotov na osnove mivarnogo podhoda"], Radio industry, No. 3, pp. 226-242.

16. Varlamov O.O., Chuvikov D.A. (2015), The use of mivar-based approach for solving problems related to simulation modelling, Seventh All-Russia scientific-practical conference "Simulation modelling. Theory and Practice "(IMMOD 2015) Proceedings of the conference: In 2 vol. Trapeznikov's Institute of Control Sciences of Russian Academy of Sciences, Edited by Vasilyev S.N., Yusupova R.M., Moscow, pp. 280-284.

17. Chuvikov D.A. (2015), "Procedural animation application in solving intelligent tasks and problems related to situational three-dimensional 
modelling" ["Primenenie procedurnoj animacii v reshenii intellektual'nyh zadach i problem, svyazannyh s situacionnym trekhmernym modelirovaniem"], Radio industry, No. 3, pp. 184-190.

18. Chuvikov D.A. (2015), "Physics engine application in solving tasks related to situational three-dimensional modelling" ["Primenenie fizicheskogo dvizhka v reshenii zadach, svyazannyh s situacionnym trekhmernym modelirovaniem $v$ real'nom vremeni'], Radio industry, No. 3, pp. 191-199.

19. Chuvikov D.A. (2015), "Graphics engine application in solving intelligent tasks related to situational three-dimensional modelling" ["Primenenie graficheskogo dvizhka v reshenii intellektual'nyh zadach, svyazannyh s situacionnym trekhmernym modelirovaniem"], Radio industry, No. 3, pp. 200-209.

20. Varlamov O.O. (2002), Evolutionary databases and knowledge bases for adaptive synthesis of intelligent systems. Mivar-oriented information space. [Evolyucionnye bazy dannyh i znanij dlya adaptivnogo sinteza intellektual'nyh sistem. Mivarnoe informacionnoe prostranstvo], Radio and communications, Moscow, 288 p.

\section{DATA ABOUT THE AUTHORS}

Chuvikov Dmitry Alekseevich, Postgraduate Student, Department of «Automated Control Systems»

State Technical University - MADI

64, Leningradsky prospekt, Moscow, 125319, Russian Federation

d.chuvikov@mivar.ru

Nazarov Konstantin Vladimirovich, Graduate Student, Department IU5 «Automated Systems of Information Processing and Control» Bauman Moscow State Technical University

5, 2 Baumanskaya Str., 5, Moscow, 105005, Russian Federation k.nazarov@mivar.ru 